\title{
A ESCRITA COMO AUTOFORMAÇÃ̃O E RESISTÊNCIA: FOUCAULT, NIETZSCHE E A CRIAÇÃO DE MUNDOS E HISTÓRIAS
}

\author{
Bruno Abilio Galvão ${ }^{1}$ \\ Universidade do Estado do Rio de Janeiro (UERJ) \\ https://orcid.org/0000-0003-2812-8623 \\ E-mail: brunoabiliogalvao@hotmail.com
}

\section{RESUMO:}

A ficção corresponde a um estilo de escrita que sustenta a construção de narrativas capazes de arrancar o escritor de si mesmo em um sentido de, por meio do experimento da própria linguagem, constituir-se esteticamente. Quando observamos as obras de Nietzsche, percebemos que há uma pluralidade de estilos literários, compostos, frequentemente, por aforismos que demandam outro performático: a escrita hiperbólica. Por meio da escrita artística, Nietzsche cria um mundo compreendido como vontade de poder em que dá a si mesmo como personagem dentre outros tipos psicológicos. Já na filosofia de Foucault o traço marcante de suas obras é o tom histórico com o qual aborda seus temas. Porém, como o próprio afirma em algumas entrevistas, não escreve outra coisa que não sejam ficções, seleciona e organiza enunciados históricos criando diversos cenários, sujeitos e objetos de seu discurso. Este estilo presente em ambos entra em contato com o exterior provocando um reposicionamento do leitor, que é afetado promovendo, como efeito de subjetivação, um reposicionamento político de insubmissão de não querer mais ser governado dessa forma.

PALAVRAS-CHAVE: Autocriação; Escrita; Ficção; Foucault; Nietzsche; Resistência.

\section{THE WRITING AS AUTOFORMATION AND RESISTANCE: FOUCAULT, NIETZSCHE AND THE CREATION OF WORLDS AND HISTORIES}

\begin{abstract}
:
The fiction corresponds to a style of writing that supports the construction of narratives capable of wrestling the writer from himself in a sense that, through the experiment of language itself, it constitutes aesthetically. When we observe the works of Nietzsche, we perceive that there are a plurality of literary styles, often composed by aphorisms that demand another performance: hyperbolic writing. Through artistic writing, Nietzsche creates a world understood as the will to power in which he gives himself as a character among other psychological types. Already in Foucault's philosophy the striking feature of his works is the historical tone with which he approaches his themes. However, as he himself affirms in some interviews, he writes nothing but fictions, selects and organizes historical statements by creating various scenarios, subjects and objects of his speech. This style present in both contacts the outside provoking a repositioning of the reader, which is affected by promoting, as an effect of subjectivation, a political repositioning of insubmissão of not wanting to be governed in this way.
\end{abstract}

KEYWORDS: Self-creation; Writing; Fiction; Foucault; Nietzsche; Resistance.

${ }^{1}$ Doutorado em Filosofia na Universidade do Estado do Rio de Janeiro ( UERJ), Rio de Janeiro - RJ, Brasil.

GALVÃO, Bruno Abilio. A escrita como autoformação e resistência: Foucault, Nietzsche e a criação de mundos e histórias. Griot : Revista de Filosofia, Amargosa - BA, v.19, n.1, p.96-114, fevereiro, 2019. 


\title{
Introdução
}

Foucault nos mostra, em sua Hermenêutica do sujeito, que filosofar não consiste em uma prática meramente especulativa e técnica que, seguindo o método correto de especulações e operações da razão, se alcançaria uma suposta verdade. A relação dos filósofos antigos com a verdade consistia em um movimento de ascese, em que, por meio de uma série de práticas determinadas para consigo, o buscador da verdade, performaticamente, vislumbra o conhecimento.

\begin{abstract}
A ascese é o que permite, de um lado, adquirir os discursos verdadeiros, dos quais se tem necessidade em todas as circunstâncias, acontecimentos e peripécias da vida, a fim de se estabelecer uma relação adequada, plena e acabada consigo mesmo; de outro lado, e ao mesmo tempo, a ascese é o que permite fazer de si mesmo o sujeito destes discursos verdadeiros, é o que permite fazer de si mesmo o sujeito que diz a verdade e que, por esta enunciação da verdade, encontra-se transfigurado, e transfigurado precisamente pelo fato de dizer a verdade (FOUCAULT, 2006, p. 400).
\end{abstract}

Independentemente dessa "verdade" mística ser considerada como possível de existir factualmente, alguns fatores não podem ser negligenciados: primeiro, é necessário uma autoformação do sujeito em direção à verdade, este se faz, se autoproduz, se "arranca de si" remodelando-se. Esse fazer-se por meio de determinadas práticas "eleva" o sujeito à "verdade" ou esta se "revela" a ele. A elevação do sujeito ou a revelação da verdade sinalizam um ponto importante: o mundo e si mesmo não são vistos e compreendidos mais como em um momento anterior, logo, já não são os mesmos.

Sinalizo neste parágrafo o objetivo central de minhas análises: pensar como a prática de escrita na filosofia de Nietzsche e Foucault se configura não só como uma "ascese" a novas perspectivas de compreensão de mundo, mas também como um movimento de metamorfose do sujeito. Uma vez que, tanto na filosofia de Foucault quanto na de Nietzsche, somos o efeito de uma somatória de relações institucionais e culturais, deixar de ser se torna, não só autoformação mas também resistência. "Sou um experimentador no sentido em que escrevo para mudar a mim mesmo e não mais pensar na mesma coisa (da mesma forma ${ }^{2}$ ) como antes" dirá Foucault (2010, p. 290) e também Nietzsche (1995, p. 26) "pois bem, eu sou o oposto de um décadent: pois acabo de descrever a mim mesmo".

Para Foucault escrever é um "experimento" cujo efeito age diretamente na forma como compreendia determinadas questões. Escrever e pensar são correspondentes e diretamente implicados um no outro, o pensamento se faz a medida em que a escrita discorre. Foucault não escreve para comunicar aquilo que já compreende, mas sim para ganhar nova perspectiva sobre certas questões. Ganhar perspectivas, pensar diferente, significa "deixar de ser" e se formar. Deixar de ser, como Nietzsche diz confirmando Foucault, se passa pela descrição de si, descrever-se, auto narrar-se para si mesmo significa enxergar-se, compreender os efeitos da cultura constituinte em si e deixar de ser decadência. "Sem considerar que sou um décadent, sou também o seu contrário. Minha prova para isso é, entre outras, que

2 Parênteses nosso.

GALVÃO, Bruno Abilio. A escrita como autoformação e resistência: Foucault, Nietzsche e a criação de mundos e histórias. Griot : Revista de Filosofia, Amargosa - BA, v.19, n.1, p.96-114, fevereiro, 2019. 
instintivamente sempre escolhi os remédios certos contra os estados ruins" (NIETZSCHE, 1995, p. 23). "Sou um decadente", afirma Nietzsche, ou seja, "compactuo da decadência cultural a qual vivencio", mas, que pharmakon receitar a si mesmo: "descrever a mim mesmo".

Este estilo de escrita se fecha em um ciclo que articula autor, texto e leitor. $\mathrm{O}$ último é incitado, a todo instante, por meio da obra, a pensar junto com ela problematizando sua atualidade. A obra assim pensa por si, pois se desprende de seu autor que, ao escrevê-la, experimenta a realidade autoformando-se e obriga o leitor, à medida que problematiza e experimenta o presente, a autoformar-se. $\mathrm{O}$ texto, assim, opera na microfísica do poder subvertendo suas linhas de força, como ato político.

Para pensarmos estas questões o texto se desenvolverá em quatro momentos. Primeiro, visto que a questão da escrita, da política e da subjetivação pressupõe um agente, investigaremos o problema do sujeito para mostrar que este, no pensamento de ambos os filósofos, não corresponde a nenhum ente universal, dado que é impossível a multiplicidade ser enquadrada em um conceito. É imprescindível portanto evidenciar o que estes dizem com esta palavra: uma criação do discurso. Segundo, visto que o sujeito não é "real", mas sim uma figura de linguagem, indagaremos o estilo aplicado, que é a escrita como ficção. Na terceira parte a questão norteadora será mostrar como este estilo de escrita se desdobra para além do simples ato de criação, estendendo-se como prática espiritual e, por fim, elevando todas as considerações, nos debruçaremos em pensar como esta prática espiritual constitui-se, simultaneamente, como prática política.

\section{Corpo e sujeito como produção do discurso}

Vejamos que, para ambos, a escrita possui uma função espiritual de transformação do indivíduo. Mas, se sinalizamos que a metamorfose subjetiva ocorre para o sujeito e este é pensado também como corpo imerso em relações, emergem então certos problemas necessários de serem esclarecidos. Primeiro, se estamos falando de uma metamorfose do sujeito, de uma subjetividade, de um corpo, deve-se proceder com cautela para não cometermos o erro da cair em universalizações e, por conseguinte, recuarmos na história da filosofia. Não há um sujeito universal para esses filósofos e muito menos a proposta de um "corpo" com determinados funcionamentos, pois, como Foucault afirma em seu único texto sobre Nietzsche,

Pensamos em todo caso que o corpo tem apenas as leis de sua fisiologia, e que ele escapa à história. Novo erro; ele é formado por uma série de regimes que o constroem; ele é destroçado por ritmos de trabalho, repouso e festa; ele é intoxicado por venenos - alimentos ou valores, hábitos alimentares e leis morais simultaneamente; ele cria resistências. A história efetiva se distingue daquela dos historiadores pelo fato de que ela não se apoia em nenhuma constância: nada no homem - nem mesmo seu corpo é bastante fixo para compreender outros homens e se reconhecer neles (FOCAULT, 2010, p. 27).

Portanto, pensar a subjetivação por meio da prática da escrita constitui não adotar uma origem fixa e, por origem, nem Deus nem homem, pois estas substâncias 
não compreendem a mutabilidade. Dessa forma, falar de uma transfiguração do eu partindo de um sujeito ou corpo preexistente consistiria em uma contradição com nossos objetivos. Como falar de um "eu" sem universalizações? A prática genealógica e também a arqueológica se utilizam de documentos, enunciados, portanto, todos os sujeitos e corpos falados nos discursos de Nietzsche e Foucault emergem do próprio discurso.

"E quanto ao Eu! Tornou-se uma fábula, uma ficção, um jogo de palavras: cessou inteiramente de pensar, de sentir e de querer!... Que resulta disso? Não há causas mentais absolutamente!" (NIETZSCHE, 2006, p. 41). Vejamos que Nietzsche reduz o sujeito a uma criação fictícia de um "jogo de palavras", o sujeito, como fundamento transcendental, emerge a partir dos discursos que o constroem. $O$ problema que assinala é que essa ficção transcendental é tomada como realidade. Retomando tal perspectiva, Foucault, na obra $A$ arqueologia do saber, ao descrever os elementos do discurso e suas construções a partir de enunciados, se pergunta: "quem fala? Quem, no conjunto de todos os sujeitos falantes, tem boas razões para ter esta espécie de linguagem? Quem é seu titular?" (FOUCAULT, 2008, p. 56). Quem no discurso clínico é aquele que fala? O médico, mas, como dizer quem é o médico? E, se há como falar, como ele é narrado por Foucault?

\begin{abstract}
Na análise proposta, as diversas modalidades de enunciação, em lugar de remeterem à síntese ou à função unificante de um sujeito, manifestam sua dispersão: nos diversos status, nos diversos lugares, nas diversas posições que pode ocupar ou receber quando exerce um discurso, na descontinuidade dos planos de onde fala. Se esses planos estão ligados por um sistema de relações, este não é estabelecido pela atividade sintética de uma consciência idêntica a si, muda e anterior a qualquer palavra, mas pela especificidade de uma prática discursiva (FOUCAULT, 2008, p. 61).
\end{abstract}

Vejamos aqui como Foucault retoma a postura de Nietzsche em relação ao sujeito, o médico, que é uma modalidade enunciativa, não indica um sujeito específico, mas sim uma dispersão de enunciados que se cruzam possibilitando a emergência do sujeito falante. Portanto, ambos apontam o sujeito como uma construção do discurso, o sujeito é uma função fictícia que emerge no discurso a partir de um jogo de enunciados que exerce ora funções de fala ora relações de poder. Se retomarmos Foucault em $O$ poder psiquiátrico, quando fala do corpo, mostra, claramente, que este ocupa no discurso a função sujeito, ou seja, sempre quando se refere a corpo, este ocupa uma posição de sujeito no discurso e corresponde ao mesmo, uma criação fictícia do jogo de palavras e enunciados.

\begin{abstract}
No poder disciplinar, pelo contrário, a função sujeito se ajusta exatamente à singularidade somática: o corpo, seus gestos, seu lugar, seus deslocamentos, sua força, o tempo de sua vida, seus discursos, sobre tudo isso se aplica e se exerce a função sujeito do poder disciplinar. A disciplina é a técnica de poder pela qual a função sujeito se sobrepõe e se ajusta exatamente à singularidade somática (FOUCAULT, 2007a, p. 77).
\end{abstract}

E na primeira aula desse curso do College de France destaca que:

GALVÃO, Bruno Abilio. A escrita como autoformação e resistência: Foucault, Nietzsche e a criação de mundos e histórias. Griot : Revista de Filosofia, Amargosa - BA, v.19, n.1, p.96-114, fevereiro, 2019. 
O que é esse médico? E bem, aqui parece, agora, uma vez que o paciente foi transferido para o asilo pelas surpreendentes máquinas das quais lhes falava recentemente. Sim, tudo isto é uma descrição fictícia, enquanto a construo a partir de uma série de textos que não pertencem a um solo psiquiatra (FOUGAULT, 2007a, p. 18).

Então, "o que é esse médico?" e como falar dele considerando a inserção dos enfermos nos asilos? Por meio de uma construção fictícia a partir de uma série de textos disperso que não correspondem ao solo da psiquiatria. Se por um lado Foucault constrói as modalidades enunciativas de seus discursos, por outro Nietzsche trabalha com a ideia de tipos psicológicos que não correspondem a um sujeito específico, mas sim a traços característicos culturalmente moldados que corresponde a formas de experimentação do mundo das quais os indivíduos compartilham. Dessa forma, quando Nietzsche utiliza o nome de Wagner em suas obras não se direciona a pessoa dele, os "nomes próprios, e estes não são nem representações de coisas (ou pessoas), nem representações de palavras (...) mas designações de intensidade, sobre um corpo que pode ser o corpo da terra, o corpo do livro, mas também o corpo sofredor de Nietzsche" (DELEUZE, 1985, p. 63). Portanto, Nietzsche quando utiliza um nome como o de Wagner ou de Schopenhauer está designando determinados elementos culturais que influenciam o modo como as pessoas vivem. Nietzsche diz: "nunca ataco as pessoas" e também, um pouco mais adiante, "assim ataquei Wagner, ou mais precisamente a falsidade, a bastardia de instinto de nossa 'cultura', que confunde os sofisticados com os ricos, os tardios com os grandes" (NIETZSCHE, 1995, p.32).

Portanto, ambos vetam-se ao trabalho de descrever ou procurar solucionar a questão do sujeito como realidade fixa, como corpo que vive no mundo, mas sim, todos os nomes, todos os indivíduos, sujeitos, correspondem a figuras de linguagem que ocupam determinada função no discurso. Não há a possibilidade para uma descrição factual do mundo, não há coisas, nem condições e nem perspectivas imutáveis. Dessa forma, a maneira que resta a esses filósofos para falar do "mundo" é por meio de uma construção discursiva e narrativa que se assume como ficção, como criação e experimentação de mundo.

\section{A escrita como ficção: criação de mundos e histórias}

A partir da linguagem ficcional que nos deparamos, esta demarca a necessidade de flexionar, de dobrar esse ponto de chegada sobre si mesmo e investigarmos esta questão. O que é fazer filosofia utilizando-se do discurso da ficção? Que estilística ou performance sustenta a construção dessas narrativas capazes de arrancar o escritor de si mesmo?

Quando observamos as obras de Nietzsche, percebemos que há uma pluralidade de estilos literários, porém, segundo Nehamas (2002), há comentadores que propõe o aforismo como estilo predominante. $O$ autor defende que o aforismo, embora seja um recurso bastante utilizado nos escritos de Nietzsche, não permite estabelecer um fio estilístico que perpassasse por toda a sua obra. Propõe que os aforismos demandam outro elemento com o qual encerram sua possibilidade performática: a escrita hiperbólica. A hipérbole, recurso presente desde Nascimento 
da tragédia à Ecce homo é o recurso comumente utilizado por Nietzsche. Este recurso linguístico tem por efeito um contato com o exterior, "a hipérbole se adequa particularmente bem ao estilo aforístico porque contribui para que o aforismo atraia nossa atenção e, mediante sua capacidade de surpresa, revela conexões absolutamente inesperadas" (NEHAMAS, 2002, p. 42), ou, nas palavras de Deleuze (1985, p. 60), da escrita de Nietzsche "alguma coisa salta do livro, entra em contato com um puro exterior". Vejamos que a hipérbole é propositalmente escolhida segundo um objetivo, afetar o leitor e induzi-lo a vivenciar a intensidade presente em seu texto. Dessa forma, Nietzsche se aproxima muito mais da escrita literária e artística do que o dogmatismo da escrita filosófica e científica, "o pensamento de Nietzsche se modela, como sempre, em função do conceito que tem da literatura e das artes" (NEHAMAS, 2002, p. 269).

Portanto, Nietzsche fala sobre o "mundo" a partir de uma criação artística, pois as descrições de mundo com pretensões universais são sempre perspectivas e valorativas. Se há a criação de mundo esteticamente, em hipótese alguma os elementos do discurso de Nietzsche correspondem às coisas em si mesmas e, como já assinalamos na primeira parte, o eu é sempre uma construção do jogo de enunciados. Dessa forma, os diversos sujeitos e inclusive o próprio Nietzsche são personagens criados para sua trama. Todos os nomes próprios, assinaturas que aparecem não correspondem a pessoas, mas sim designam forças

\begin{abstract}
A intensidade tem algo a ver com os nomes próprios, e estes não são nem representações de coisas (ou pessoas), nem representações de palavras. Coletivos ou individuais, os pré-socráticos, os romanos, os judeus, o Cristo, o Anticristo, Júlio Cesar, Bórgia, Zaratustra, todos estes nomes próprios que passam e retornam nos textos de Nietzsche, não são nem significantes nem significados, mas designações de intensidade, sobre um corpo que pode ser corpo da terra, o corpo do livro, mas também o corpo sofredor de Nietzsche: todos os nomes da história, sou eu... (DELEUZE, 1985, p. 63).
\end{abstract}

Além da hipérbole, dos aforismos, dos personagens históricos transfigurados em figuras de linguagem, o estilo de Nietzsche se direciona para a construção discursiva do próprio sujeito Nietzsche

Uma maneira de alcançar esta meta acaso inalcançável poderia consistir em escrever um amplo número de excelentes livros que aparentam graves inconsistências mútuas porém que, lidos atentamente e com discernimento, revelam um profundo fio condutor. Para no final deste empenho, alguém pode escrever um livro a propósito destes livros no que revele como se encaixam todos, como através de todo o conjunto, se destaca uma figura única, como até as contradições mais severas tem sido acaso necessárias para que essa figura, o personagem, o autor, a pessoa (a palavra não tem a maior importância aqui) surja com toda nitidez através desses livros (NEHAMAS, 2002, p. 233).

Assim, a ficção para Nietzsche aparece como possibilidade não dogmática devido à sua variabilidade de gêneros literários utilizando a hipérbole como recurso de afeto ao exterior valendo-se, em grande parte, do recurso dos aforismos. Portanto, os cenários da genealogia nietzschiana, hiperbólicos, "são criados de forma altamente 
artificial, fazendo uso de metáforas imaginativas e ilustrações coloridas" (SAAR, 2008 , p. 308).

Já na filosofia de Foucault o traço marcante de suas obras é o tom histórico com o qual aborda seus temas. Porém, como ele mesmo afirma, muitos admiradores de seu trabalho, ao lerem, comentam rindo: "no fundo, você sabe bem que o que diz não passa de ficção" (FOUCAULT, 2010a, p. 292). E ele sempre responde: "Certamente, não se trata de questão que seja outra coisa senão ficções" (FOUCAULT, 2010a, p. 292).

O que isso significa? Significa dizer que obras como História da loucura, Vigiar e punir e História da sexualidade não são livros de história efetivamente. Isto não significa dizer que os enunciados utilizados em suas obras sejam falsos, estes existem, são reais, a questão está na maneira como ele seleciona determinados enunciados e os organizam, criando diversos cenários históricos. Quanto a isso Foucault, como diz Deleuze (2005), é um artista capaz de "pintar" quadros. Por essa razão Foucault não adota uma tipologia específica de livros e textos em seu campo de pesquisas, ora utiliza regulamentações institucionais, ora literatura, ora textos de filosofia, textos científicos, etc. Não há hierarquizações de discursos à outros de acordo com gêneros, todos se equivalem enquanto possibilidade de seleção e recorte com os quais Foucault cria os sujeitos e objetos de seu discurso.

Mas que linguagem ou estilo de escrita é esse que Foucault denomina de ficção? Foucault, ao organizar os enunciados históricos na sua prática arqueológica e genealógica, tem por objetivo fazer com que vejamos algo com o qual lidamos cotidianamente de forma normalizada ou naturalizada. Portanto, a ficção é um estilo de discurso que "faz ver".

Observemos um trecho do suplício de Damiens em Vigiar e punir:

Depois desses suplícios, Damiens, que gritava muito sem contudo blasfemar, levantava a cabeça e se olhava; o mesmo carrasco tirou uma colher de ferro do caldeirão daquela droga fervente e derramou-a fartamente sobre cada ferida. Em seguida, com cordas menores se ataram as cordas destinadas a atrelar aos cavalos, sendo estes atrelados a seguir a cada membro ao longo das coxas, das pernas e dos braços [...].

Uma vez retiradas as quatro partes, desceram os confessores para lhe falar; mas o carrasco informou-lhes que ele estava morto, embora, na verdade, eu visse que o homem se agitava, mexendo o maxilar inferior como se falasse. Um dos carrascos chegou mesmo a dizer pouco depois que, assim que eles levantaram o tronco para o lançar na fogueira, ele ainda estava vivo $[\ldots]$

... Em cumprimento da sentença, tudo foi reduzido a cinzas. O último pedaço encontrado nas brasas só acabou de se consumir às dez e meia da noite (FOUCAULT, 2007b, p. 09-10).

Embora se tratasse de uma forma de punição histórica, Foucault utiliza uma narrativa emocionalmente carregada, com personagens e lugares específicos, somados a uma plateia anônima. A linguagem como narrativa ou ficção produz imagens flutuantes que saltam à escrita, mas essas imagens não significam a presentificação das coisas, mas sim "o que nomeia as coisas, fá-las falar e oferece na linguagem seu ser já dividido pelo soberano poder das palavras" (FOUCAULT, 2009, p. 68). A ficção se desdobra e se distancia da linguagem, é um desdobramento de 
certas palavras e dos agrupamentos de palavras e enunciados. É esse desdobramento, esse distanciamento produzido pela organização de enunciados que Foucault efetua

a simples experiência que consiste em pegar uma caneta e escrever
franqueia (como se diz: liberar, desenterrar, retomar um penhor ou
retornar a uma fala) uma distância que não pertence nem ao mundo, nem
ao inconsciente, nem ao olhar, nem à interioridade, uma distância que, em
sua nudez, oferece um quadriculado de linhas de tinta e também um
emaranhado de ruas, uma cidade começando a nascer já ali há muito
tempo (FOUCAULT, 2009, p. 69).

Desse tracejar, estimular palavras, organizar letras sobre o papel em branco, esse momento da escrita somente, essa materialidade das palavras é a "origem" da linguagem como ficção, é a origem da qual partem as imagens e cenários erguidos no discurso foucaultiano. Essas palavras, já distanciadas das coisas, pois as nomeiam, na prática discursiva produzem nos distanciamentos, um escoar a partir do fora do qual, no interior da linguagem, esta não para de falar, uma linguagem sem sujeito, um discurso autônomo. O sujeito do discurso fora do discurso está cindido da linguagem. $O$ recuo absoluto da origem, da pura materialidade de traços e linhas apaga toda a ficção e o campo de objetos. $O$ recuo absoluto da origem demarca, no fora, o pensamento. Demarca portanto uma cisão entre pensamento e linguagem.

A escrita como literatura, que é a escrita como ficção, na construção a partir de enunciados e discursos de um mundo ou período histórico corresponde, em partes, ao pensamento do fora anunciado por Blanchot. Importante destacar aqui que o fora indica, nesses autores, muito mais uma postura que reconhece a autonomia do discurso e o desprendimento do autor do que a utilização de recursos literários. Por exemplo, como afirma Artières et. Al. (2016), a partir da década de 1970 os textos literários não são mais um recurso para as fontes de Foucault, porém, a postura da autonomia do discurso permanece. A análise do pensamento do fora como produção filosófica desses autores deve, suponho, ser interpretada a partir de um diálogo com Blanchot em seu texto A literatura e o direito a morte. A escrita literária aparece nesse texto como uma produção que, ao mesmo tempo, produz e é produzida pelo autor num processo de desprendimento em que o eu falo se dissolve. $\mathrm{O}$ texto aparece e veicula um pensamento autônomo por si e o nome do autor aparece mais como dispositivo de articulação das obras do que da pessoa mesmo. Por essa razão, tanto Foucault como Nietzsche, nos períodos de maturidade, dão-se máscaras que encerram o próprio nome, Nietzsche em sua obra Ecce homo e Foucault no verbete para Dictionnaire des philosopes ${ }^{3}$, onde assina como Maurice Florence.

A metamorfose ou transfiguração do autor na escrita efetuada no ato do pensamento do fora aproxima-se da visão de mundo dionisíaca ou do mundo como vontade de poder. Uma análise conjunta do pensamento do fora com o mundo como vontade de poder nos implica num risco ou na fatalidade de nossos autores serem tragados por essa ficção e, talvez, tenhamos que transformá-los em personagens, pois aparece como possibilidade a imersão dos filósofos na fábula nietzschiana. $\mathrm{O}$ mundo, tal como Nietzsche propõe, é constante impermanência, a abordagem do mundo adotando caracteres ou estruturas ontológicas se mostra como erro grotesco,

${ }^{3}$ Cf.: FOUCAULT, 2006a, p. 234-239. 
portanto, embora Nietzsche seja um criador de mundos (KLOSSOWISK, 1995), este só pode ser concebido como impermanência. O que é o mundo como vontade de poder?

Nietzsche inicia a exposição do mundo como vontade de poder indicando com uma pergunta: "E sabes o que é para mim o "mundo'?" (NIETZSCHE, 2011b, p. 453). Essa pergunta indica duas coisas, primeiro o perspectivismo de Nietzsche, o que é o mundo para mim, e segundo, mundo aparece com aspas indicando o tom irônico de Nietzsche. Para o filósofo não há uma descrição pura dos fatos mas sim perspectivos, o sentido do mundo e sua interpretação está sempre ligado a uma vontade interpretante. Portanto, o mundo como vontade de poder é a apresentação de um ponto de vista que procura descrever um mundo como impermanência e, por autocompreender-se como perspectivo, apresenta esta como uma dentre outras compreensões de mundos possíveis. Em que consiste esse mundo?

\footnotetext{
Este meu mundo dionisíaco da eterna criação de si mesmo, da eterna destruição de si mesmo, este mundo misterioso das voluptuosidades duplas, meu 'além do bem e do mal' sem fim, senão o fim que reside na felicidade do círculo, sem vontade, senão um anel que possua a boa vontade de seguir seu velho caminho, sempre em redor de si mesmo e nada mais senão em redor de si mesmo (NIETZSCHE, 2011b, p. 454).
}

Nesse mundo dionisíaco todas as coisas se criam e se dissolvem estabelecendo um movimento circular, esse mundo que ele propõe como espelho, como imagem refletida pressupõe um interlocutor que, diante do terror do círculo, não restaria outra possibilidade que "ofertar a si mesmo ao "anel dos anéis", ou seja, assumir-se como impermanência, como finitude, como constante criação e dissolução, pois "vós também sois esta vontade de potência e nada mais..." (NIETZSCHE, 2011b, p. 454). Assim como o "mundo" as perspectivas, as identidades, os "eus" se dissolvem em um movimento de recriação de si mesmo e, por acaso, não foi o próprio Foucault que disse "não me pergunte quem sou e não me diga para permanecer o mesmo" (FOUCAULT, 2008, p. 20)? Vejamos que, nessa altura do texto, ficção e "realidade" se confundem, pois construímos um Nietzsche e um Foucault tal como um mundo de impermanências, tal como um "mundo" como vontade de poder. Nietzsche e Foucault dobram-se diante da imagem de Dionísio.

\section{A escrita como espiritualidade e transfiguração}

Dos enunciados recolhidos e organizados emergem as figuras de Foucault e Nietzsche como filósofos cujo pensamento é indissociável da escrita e, por meio desta, metamorfoseiam-se. Porém, como pensar ou compreender um estilo de vida ao qual se busca praticar? A forma mais coerente com o que expomos até o momento é fazer o próprio processo falar por si mesmo. Portanto, descrever o ato de filosofar como uma estética da existência é uma forma de compreender ou pensar a prática que estabelece. Assim, os filósofos mascaram-se com os rostos de seus personagens buscando uma autonarrativa. Narrar a história, narrar os diversos tipos psicológicos, narrar as redes de relações estabelecidas é narrar a si mesmo pois a subjetividade é constituída a partir da interação com tudo o que a rodeia. $\mathrm{O}$ sujeito é o resultado de 
uma somatória de efeitos. Analisaremos, nessa etapa, por meio das obras Assim falava Zaratustra e Hermenêutica do sujeito, o processo de subjetivação a partir de uma relação consigo mesmo.

Zaratustra, ou melhor, Nietzsche mascarado, narra uma trajetória de autossuperação por meio do personagem. Por autossuperação compreende-se, primeiro, uma compreensão de si mesmo a partir de um olhar que mapeia a identidade provocando a emergência de determinados "nós" na rede constitutiva do eu. Segundo, uma dissolução desses nós a partir de um diálogo de si para consigo e, terceiro uma visão coesa de si implicando a reconciliação consigo mesmo a partir de um ganho de perspectiva. $O$ personagem, nesse processo de subjetivação, evidencia quatro momentos. Primeiro, Zaratustra caminha em direção à sua solidão. $O$ caminhar aparece, em determinados momentos, como escalada, Zaratustra é o que impõe a si mesmo um percurso. Mas que percurso é este, que estrada é esta percorrida por Zaratustra? Se Zaratustra é uma das máscaras de Nietzsche e caminho indica um processo de subjetivação, Nietzsche, ao movimentar Zaratustra por meio de sua narrativa faz, concomitante a escrita e o desdobramento da ficção, o mesmo caminho. Se Nietzsche opta por Zaratustra ou veste-se dessa roupagem, pressupõe-se uma vivência "compartilhada". Por que Zaratustra?

\footnotetext{
Não me foi perguntado, deveria me ter sido perguntado, o que precisamente em minha boca, na boca do primeiro imoralista, significa o nome Zaratustra: pois o que constitui a imensa singularidade deste persa na história é precisamente o contrário disso. Zaratustra foi o primeiro a ver na luta entre o bem e o mal a verdadeira roda motriz na engrenagem das coisas - a transposição da moral para o metafísico, como força, causa, fim em si, é obra sua. Mas essa questão já seria no fundo a resposta. Zaratustra criou este mais fatal dos erros, a moral: em consequência, deve ser também o primeiro a reconhecê-lo (NIETZSCHE, 1995, p. 110-111).
}

Nietzsche atribui a Zaratustra a tarefa de superar a moral, ou seja, a finalização de um ciclo iniciado pelo próprio. Da mesma forma Nietzsche, emergido do seio da filosofia, é o primeiro imoralista. Ele se coloca dessa maneira como um marco que divide a história da filosofia, um período moral e um em que esta é transvalorada. Tenhamos claro que Nietzsche não quer, de maneira alguma, excluir definitivamente todo tipo de valores, pois a valoração das ações estão ligadas com as perspectivas daqueles que criam valores e estas decorrem das forças que se digladiam constantemente. Que valores são esses que Nietzsche deixa para trás? Importante destacar que só é deixado para trás aquilo que é "carga", aquilo que carregamos, portanto, Nietzsche compreende-se como constituído por esses valores cujos quais procura desprender-se. A autonarrativa, por meio da ficção, permite uma dissolução da identidade do autor que, pela escrita, dialoga consigo mesmo. Essa caminhada, segundo Fogel é 
velada da filosofia', isto é, do Ocidente, da Europa. Esse pensamento fala, mostra o ocidente do Ocidente (FOGEL, 2010, p. 60).

Vejamos que Zaratustra é a tentativa ou assunção da tarefa de, por meio da autonarrativa, superar, em si, os valores cunhados historicamente no solo da metafísica dos quais ele, enquanto filho dessa tradição, vivencia. A caminhada de superação dos ideais metafísicos experimenta, no pensamento de Nietzsche, solidão. "Todas essas coisas mais que pesadas o espírito resistente toma sobre si" (NETZSCHE, 2011a, p. 28), ou seja, para sua jornada carrega-se de todo o peso da metafísica e "semelhante ao camelo que ruma carregado para o deserto, assim ruma ele para seu deserto. Mas no mais solitário deserto [...]" (NETZSCHE, 2011a, p. 28). Na solidão, no encontro consigo mesmo se é capaz de escuta. A escuta, ainda seguindo Fogel (2010, p. 54),

é o nome da concentração na coerção da dor; é o nome do recolhimento e do consentimento nesse movimento de descida ao fundo e que revela. [...] É na escuta, é nesse recolhimento, que é doação e exposição à coisa, isto é, à dor, que se fazem doação e exposição à transcendência $[. .$.$] .$

Escuta, significa, segundo a perspectiva de Fogel, pensar, pensar a partir da própria coisa pois se experimenta por meio da escuta. Escuta, dessa forma, corresponde a escrita. Por meio da escrita o pensamento se organiza e ganha corpo, por meio da escrita, que é escuta, o escritor se transfigura, transcende determinadas condições e adquire nova perspectiva.

Um filósofo que percorreu muitas saúdes e sempre as torna a percorrer passou igualmente por outras tantas filosofias: ele não pode senão transpor seu estado, a cada vez, para a mais espiritual forma e distância precisamente esta arte de transfiguração é filosofia (NIETZSCHE, 2001b, p. 12).

Uma nova constituição de si, uma nova perspectiva, novos valores, novas relações. A escuta faz ver e, ao ver, falar. "Apenas a vós relato o enigma que vi - a visão do mais solitário" (NIETZSCHE, 2011a, p. 148).

Vejamos que, para poder "ver" e consequentemente, "falar", pronunciar o enigma, Zaratustra se submete a determinadas práticas que lhe possibilitam "acessar" o enigma. $O$ enigma consiste em uma visão de mundo, uma perspectiva que pretende ser o ultrapassamento da metafísica. $O$ anúncio do eterno retorno por meio da metáfora do portal apresenta um tipo de subjetividade móvel e, ao final do vislumbre, o sujeito aparece transfigurado como pastor que, ao decepar com os dentes a cabeça da serpente que o sufoca, aparece diferenciado de si. Nietzsche usa essa metáfora para indicar um processo de subjetivação que se efetiva mediado por práticas auto impostas: a caminhada, a solidão, o silêncio, a escuta, cujo efeito é um ganho de perspectiva, o enigma, e a autossubjetivação, "não mais um pastor, não mais um homem - um transformado, um iluminado que ria!" (NIETZSCHE, 2011a, p. 152).

Foucault, de certa forma, retoma esse tema em sua Hermenêutica do sujeito, localizando Nietzsche em uma tradição mais expandida: a que coincide aquisição do conhecimento com espiritualidade. 
Retomemos toda a filosofia do século XIX - enfim, quase toda: Hegel certamente, Schelling, Schopenhauer, Nietzsche o Husserl da Krisis, também Heidegger - e veremos precisamente que, seja desqualificado, desvalorizado, considerado criticamente, seja, contrário, exaltado como em Hegel, de todo modo porém, o conhecimento, o ato de conhecimento permanece ainda ligado às exigências da espiritualidade. Em todas estas filosofias, há uma certa estrutura de espiritualidade que tenta vincular o conhecimento, o ato de conhecimento, as condições deste ato de conhecimento e seus efeitos, a uma transformação no ser mesmo do sujeito (FOUCAULT, 2006b, p. 38).

Em sua genealogia da ética Foucault mostra como a subjetividade se constitui a partir de uma relação do sujeito consigo mesmo. O processo de subjetivação, denominado por espiritualidade, consiste na relação do indivíduo com a verdade, porém, esta verdade ainda não está dada, está, de certa maneira, distante do indivíduo. Há, segundo Foucault, um preço a se pagar para acessá-la. Este preço é o comprometimento do sujeito para com ela, colocando em jogo seu próprio, dissolvendo e reformulando sua identidade. Esse processo de subjetivação se dá mediante determinadas práticas, "tais como as purificações, as asceses, as renúncias, as conversões do olhar, as modificações de existência". Este cuidado para consigo é o preço a se pagar para acessar a verdade. "A espiritualidade postula que a verdade jamais é dada de pleno direito ao sujeito" (FOCAULT, 2006b, p. 19).

Foucault está comunicando em sua genealogia da ética um tipo de experiência que procura, ele mesmo, vivenciar por meio de suas obras. Foucault, assim como Nietzsche, é um experimentador, vivencia, ao discorrer seus textos, determinados temas numa tentativa de não mais pensar determinados assuntos como se pensava antes. Vejamos que a escrita e seu estilo ficcional funciona como dispositivo de olhar ou escuta sobre si que possibilita uma formação da própria personalidade. Essa experiência que arranca o sujeito de seu atual status modificando-o Foucault chama de experiência limite que, como define,

tem por função arrancar o sujeito de si próprio, de fazer com que não seja mais ele próprio ou que seja, levado ao seu aniquilamento ou a sua dissolução. É uma experiência de dessubjetivação. [...] em que [...] meus livros, eu os tenha sempre concebido como experiências diretas, visando a me arrancar de mim mesmo, a me impedir de ser o mesmo (FOUCAULT, 2010a, p. 191).

A experiência limite se mostra então como conceito fundamental para pensarmos a questão política, pois um pensamento crítico, que é sempre a coerção do olhar sobre a atualidade e, consequentemente, sobre nós mesmos, sempre põe em jogo uma relação de subjetivação tanto do escritor quanto de seu leitor. Como Foucault mostra em suas análises do poder, a situação estratégia, a organização de um governo, se dá a partir da articulação de diversas táticas e relações de poder. Portanto, pensar o surgimento de pontos de insubmissão refletida consiste, primeiro, em um processo de transformação dos sujeitos em que diversos nódulos na teia do poder adquiram outras polaridades. Evidencio que a abordagem de tal assunto se mantém no campo da construção ficcional que o discurso me permite e que pensar a 
escrita como ato político e formador na prática desses filósofos implica arrastá-los para dentro de suas ficções.

\section{A filosofia crítica de Nietzsche e Foucault como movimento subversivo}

Como fundamentar a modificação social? Ambos os filósofos mostram uma relação entre poder e constituição da subjetividade, o sujeito é sempre produto de uma rede estratégica que perpassa todos os corpos estabelecendo vetores de força. Força aqui indica direcionamento da ação em um campo coordenado. Tanto na genealogia da moral nietzschiana como nas genealogias do poder de Foucault, por meio da hipótese levantada ficcionalmente lançando mão de enunciados históricos, o poder se torna algo visível e inteligível (SAAR, 2008). E esta é exatamente a questão posta por Foucault, compreender o poder e sua dinâmica, saber, ver seu funcionamento e, por conseguinte, incitar uma série de movimentos subversivos. Assim como Foucault diz em sua conversa com Deleuze, Os intelectuais e poder, demorou-se muito para se compreender os regimes e relações e exploração no capitalismo (século XIX). Visualizar as forças "secretas" é, talvez, a grande função dessas filosofias.

\footnotetext{
O discurso de luta não se opõe ao inconsciente: ele se opõe ao segredo. Isso dá a impressão de ser muito menos. E se fosse muito mais? Existe uma série de equívocos a respeito do 'oculto', do 'recalcado', do 'não dito' que permite 'psicanalisar' a baixo preço o que deve ser o objeto de uma luta. $O$ segredo é talvez mais difícil de revelar que o inconsciente. Os dois temas ainda há pouco frequentes - 'a escritura é o recalcado' e 'a escritura é de direto subversiva' - me parecem revelar certo número de operações que é preciso denunciar implacavelmente (FOUCAULT, 2010b, p. 76).
}

Portanto, essa filosofia da qual compartilham é muito mais uma atitude, uma postura, do que simplesmente uma semelhante forma de teorizar. Essa postura se chama ora de crítica da atualidade, ora de história ou ontologia do presente.

Em 1984 em um texto chamado "Qu'est - ce que les Lumières?" (O que é o Esclarecimento?), Foucault vincula seu trabalho a uma tradição mais ampla da qual Nietzsche faz parte: "é essa forma de filosofia que, de Hegel à Escola de Frankfurt, passando por Nietzsche, Max Weber, tem fundado uma forma de reflexão na qual eu tenho experimentado trabalhar" 4 (FOUCAULT, 1994, p. 688). A finalidade de Foucault não é, assim como a de Nietzsche valendo-se da práxis genealógica, uma história efetiva dos fatos do passado. O compromisso de Foucault é com a atualidade, com o presente, por essa razão se intitula herdeiro de uma tradição inaugurada por Kant e reassumida por Nietzsche que procura compreender e problematizar a atualidade. A pergunta inaugural dessa tradição, "O que é o esclarecimento?" significa, na interpretação foucaultiana, uma pergunta sobre o êthos moderno, "o que somos nós na atualidade?", "o que somos nós enquanto aqueles que vivenciam o esclarecimento?". A história escrita por Foucault é sempre uma "história do presente" e se adota a terminologia nietzschiana da história efetiva, a

${ }_{4}^{4}$ Tradução minha.

GALVÃO, Bruno Abilio. A escrita como autoformação e resistência: Foucault, Nietzsche e a criação de mundos e histórias. Griot : Revista de Filosofia, Amargosa - BA, v.19, n.1, p.96-114, fevereiro, 2019. 
efetividade dessa história, que é ficção, está na funcionalidade de provocar a problematização da atualidade em seus leitores.

\begin{abstract}
Meu problema era de fazer eu mesmo, e de convidar os outros a fazerem comigo, através de um conteúdo histórico determinado, uma experiência do que somos, do que é não apenas nosso passado, mas também nosso presente, uma história de nossa modernidade de tal forma que saíssemos transformados. O que significa que, ao final do livro, pudéssemos estabelecer relações novas com o que está em questão: que eu, que escrevi o livro, e aqueles que o leram tivéssemos em relação à loucura, ao seu status contemporâneo e à sua história no mundo moderno um outro relacionamentos (FOUCAULT, 2010, p. 292).
\end{abstract}

Correspondentemente, a postura crítica na genealogia nietzschiana se direciona aos valores que se tornaram, durante um longo período de tempo, autoevidentes, ou seja, princípios não questionados dos quais o pensamento filosófico e até mesmo outros elementos culturais se desenvolvem ${ }^{5}$. É evidente, para Nietzsche (2001b), que até o momento presente de sua vida a moral nunca fora colocada como um problema, ela sempre foi mantida imperturbável em seu espaço neutro, imune, o que inviabilizava uma crítica dos valores morais.

Há, para Nietzsche (2001b), uma diferença considerável entre um pensador que toma pessoalmente posição diante de seus problemas, a ponto de fazer deles seu destino, seu esforço e também sua maior felicidade, e aquele que se aproxima de seus problemas de forma "impessoal". Nietzsche diz que o problema da moral é compartilhado tanto por ele como pelos demais pensadores dos quais se distingue, porém, a diferença se encontra na postura adotada diante da questão: se a moral de um povo se dá no acoplamento de juízos de valor a costumes, e se Nietzsche, assim como os demais pensadores é parte de um "povo" que julga e age segundo valores que não possuem nenhuma origem em um bem extra-humano, mas sim em uma vontade de poder, a diferença se dá em assumir ou não esse problema. Como ser "impessoal" em uma situação que lhe exige, sempre, uma determinada particularidade compartilhada?

O problema da moral tal como Nietzsche o coloca, embora seja, assim como o próprio admite, uma questão que assume para si, defende que essa perspectiva que alcançou pode ser compartilhada:

não temos o direito de atuar isoladamente em nada: não podemos errar isolados, nem isolados encontrar a verdade. Mas sim, como necessidade com que uma árvore tem seus frutos, nascem em nós nossas ideias, nossos valores, nossos sins e nãos e ses e quês - todos relacionados e relativos uns aos outros, e testemunhas de uma vontade, uma saúde, um terreno, um sol (NIETZSCHE, 1998, p. 08).

\footnotetext{
${ }^{5}$ Como exemplo, indicamos a leitura do aforismo dois da primeira parte: Dos preconceitos dos filósofos, de Além do bem e do mal, em que Nietzsche diz que os filósofos (metafísicos) a partir de uma crença formulada por um processo lógico em que não concebem uma coisa como proveniente de seu contrário (a verdade proveniente do erro, por exemplo), criam uma hierarquia de valores e estabelecem isso como princípio de interpretação do qual submetem o mundo. A verdade, apontada pelos filósofos (metafísicos) como valor último da realidade, é o quesito com o qual julgam os diversos costumes e ordenam seu pensamento constituindo um preconceito, ou seja, algo inquestionável do qual procede todas as formulações lógicas dos filósofos. Cf. em NIETZSCHE, F. Além do bem e do mal. Tradução de Paulo César de Souza. São Paulo: Companhia das Letras, 2001a, p. 10-11.
}

GALVÃO, Bruno Abilio. A escrita como autoformação e resistência: Foucault, Nietzsche e a criação de mundos e histórias. Griot : Revista de Filosofia, Amargosa - BA, v.19, n.1, p.96-114, fevereiro, 2019. 
As ideias que surgem como frutos, embora relativos uns aos outros, diferentes, são testemunhas de um mesmo solo, ou seja, Nietzsche compartilha dos valores de sua época, porém sabe que possui compreensões diferentes a respeito deles. Suas ideias, embora compartilhem do mesmo terreno, estão relacionadas às demais, porém relativas, fazem parte de um dentre os vários pontos de vistas banhados pelo mesmo sol. Embora assume seu perspectivismo, sua forma de questionar, se seguida pelo interlocutor, o induz a uma perspectiva diferente daquela defendida pela tradição. Nietzsche tem o interesse de fazer com que sua crítica seja compartilhada, ("não temos o direito de atuar isoladamente em nada"):

\begin{abstract}
Quem neste ponto se detém, quem aqui aprende a questionar, a este sucederá o mesmo que ocorreu a mim - uma perspectiva imensa se abre para ele, uma nova possibilidade dele se apodera como uma vertigem, toda espécie de desconfiança, suspeita e temor salta adiante, cambaleia a crença na moral, em toda moral - por fim, uma nova exigência se faz ouvir (...): necessitamos de uma crítica dos valores morais, o próprio valor desses valores deverá ser colocado em questão (NIETZSCHE, 1998, p. 12).
\end{abstract}

Podemos perceber que Nietzsche, embora defenda sua postura com relação à crítica, procura induzir seu interlocutor ao caminho de pensamento ao qual segue. Direciona sua crítica para um estudo genealógico incitando em seu interlocutor a necessidade de um estudo da origem dos valores para que, dessa forma, seja possível avaliar a moral instituída:

\footnotetext{
E se o contrário fosse a verdade? E se no "bom" houvesse um sintoma regressivo, como um perigo, uma sedução, um veneno, um narcótico, mediante o qual o presente vivesse como que às expensas do futuro? Talvez de maneira mais cômoda, menos perigosa, mas também num estilo menor, mais baixo?... De modo que precisamente a moral seria culpada de que jamais se alcançasse o supremo brilho e potência do tipo homem? De modo que precisamente a moral seria o perigo entre os perigos?... (NIETZSCHE, 1998, p. 12-13).
}

Nietzsche, como nos diz Deleuze (1985), funda seu pensamento, seu estilo de escrita, em uma relação com o "exterior". Diferente do tradicional estilo sistemático que induz o leitor por meio de representações conceituais a resultados precisos por meio de um discurso lógico formal, a escrita de Nietzsche obriga o leitor a se posicionar de maneira a evitar a formulação de doutrinas dogmáticas. Ele induz seu leitor a dar sentido ao seu texto forçando-o ao pensamento, "Nietzsche coloca muito claramente: se você quiser saber o que eu quero dizer, encontre a força que dá um sentido, se for preciso um novo sentido ao que eu digo" (DELEUZE, 1985, p. 61).

Ao conduzir o leitor pelas correntezas que direcionam a crítica dos valores modernos, Nietzsche não entrega uma nova "tábua" com princípios morais, mas sim quer elevar (direcionar) seu leitor a alcançar a mesma postura diante da cultura, de um indivíduo capaz de criar novos valores. Há uma força que perpassa os textos de Nietzsche e afeta o exterior, "alguma coisa salta do livro, entra em contato com um puro exterior" (DELEUZE, 1985, p. 61). 


\begin{abstract}
A eficácia do incompleto. - Assim como as figuras em relevo fazem muito efeito sobre a imaginação por estarem como que a ponto de sair da parede e subitamente se deterem, inibidas por algo: assim também a apresentação incompleta, como um relevo, de um pensamento, de toda uma filosofia, é às vezes mais eficaz que a apresentação exaustiva: deixa-se mais a fazer para quem observa, ele é incitado a continuar elaborando o que lhe aparece tão fortemente lavrado em luz e sombra, a pensá-lo até o fim e superar ele mesmo o obstáculo que até então impedia o desprendimento completo (NIETZSCHE, 2000, p. 75-76).
\end{abstract}

Os textos de Nietzsche, ao darem vazão a uma força ativa induzem (forçam) o leitor a produzir sentido ou, talvez, a criar novos valores, a efetuar a crítica sem aterse a conteúdos dogmáticos. Incita a participação do leitor, o leitor de Nietzsche "não é um mero receptor de convicções, mas aquele a ser inspirado pela dissuasão" (NASSER, 2014, p.50).

Percebamos que a crítica da atualidade tem por funcionalidade criar conexões no fora. Esta, sempre, ao levantar a suspeita dos regimes de verdade e das práticas dela derivadas, convidam ou induzem o leitor a um questionamento de sua atualidade. A ficção, mediando a escrita e a leitura se torna, dessa forma, um dispositivo subversivo. Os sujeitos se subjetivam ao serem perpassados por tais discursos. Portanto, a crítica está em contraposição às artes de governar segundo regimes de verdade. Esse movimento se inicia no século XVI, no período da pastoral cristã e consistia em uma investigação das próprias escrituras, de investigação da legitimação da veiculação simbólica produzida a partir dos textos sagrados. E aqui se inicia o que Foucault compreende como atitude crítica, um movimento ou

arte de não ser governado desse modo e a esse preço. E eu proporia então, como primeira definição da crítica, essa caracterização geral: a arte de não ser governado desse modo. [...] Não querer ser governado assim era essencialmente procurar na Escritura uma outra relação além daquela que estava ligada ao funcionamento do ensino de Deus; não querer ser governado era uma certa maneira de negar, recusar, limitar (digam como quiserem) o magistério eclesiástico, era o retorno à escritura, era a questão sobre o que é autêntico na Escritura, do que foi efetivamente escrito na Escritura, era a questão sobre qual tipo de verdade que dizia a escritura, como ter acesso a essa verdade da Escritura na escritura, e apesar, talvez, do escrito; e até que se chega à questão finalmente muito simples: a Escritura era verdadeira? (FOUCAULT, 2013, p. 11).

Consequentemente, a insubmissão refletida, assim como Foucault chama esse movimento, passa a perceber certas relações como "injustas" e vê, como ilegítimo, certos preceitos de determinadas autoridades. Esse movimento de indocilidade refletida é o objetivo almejado nos trabalhos de Foucault e Nietzsche. Ao dar relevo a determinadas práticas em suas ficções, permitem evidenciar a ilegitimidade reproduzida e não percebida, o que é possível por meio de uma formação ou subjetivação do escritor e, concomitantemente, do leitor. A ficção abala o "real":

Se o sentido de qualquer criação eminente é romper com os hábitos gregários que dirigem continuamente as existências para fins exclusivamente úteis ao regime opressivo da mediocridade, no campo experimental criar é exercer violência contra o que existe e, por tanto, 
também contra a integridade dos seres. Qualquer criação inovadora deve provocar um estado de insegurança: a criação deixa de ser um jogo a margem da realidade; sucessivamente, o criador não reproduz sim que ele mesmo produz o real (KLOSSOWISK, 1995, p. 131).

Complementando com Saar (2008, p. 313):

Pode finalmente ajudar a ver que mesmo as monografias de Foucault, que se parecem completamente com a historiografia arquivística, desempenham funções que devem ser consideradas em termos de retórica e estilo e cujos objetivos práticos não são senão "ativistas": eles são para motivar a auto- reflexão e auto-revisão e para provocar resistência contra julgamentos, instituições e práticas já estabelecidas. Mostrando que suas origens e emergências são contingentes e relacionadas ao poder podem ajudar a desnaturalizá-las e desmistificar. Não é o fim, mas o começo inevitável da complexa prática social da autoridade de questionamento que chamamos de crítica.

Escrever é um ato político, um instrumento, um dispositivo operado pelo intelectual no seu espaço de atuação. Escrever é, dessa forma, um ato subversivo e local que ataca o poder fazendo-o aparecer, desmascarando-o.

\section{Conclusão}

Depreende-se desse estudo que a escrita para ambos os filósofos consiste em uma prática espiritual e também política. Nietzsche, como comenta em Ecce homo, utiliza a autonarrativa como estratégia de superar a cultura decadente da qual compartilha e Foucault a classifica como experimento da realidade. $O$ experimento da realidade ou o experimento de si produz como efeito a subjetivação do escritor na medida em que possibilita a este pensar e problematizar a atualidade. Porém, o efeito terapêutico e formador passa para a função política por meio dos estilos utilizados que, embora diferentes, a hipérbole nietzscheana e a história foucaultiana, consistem em criar ficções. A ficção, o que podemos chamar também de escrita artística ou literária, faz o leitor "ver", é como se, retomando Deleuze (1985), o cenário, a peça montada, saltasse das linhas do texto atraindo o leitor para uma ressignificação de seu mundo.

Portanto, pensando a política como vida pública, normativa, mas também ativa (cidadania), a insubmissão passa pela via do projeto do "esclarecimento", sapere aude, em que as pessoas, ao fazerem uso de sua reflexão, questionam no nível de discursos e práticas as formas de governo. Porém, dado o diagnóstico da atualidade em que há técnicas de poder que produzem uma subjetividade dócil, a escrita como ficção, na medida em que cria mundos e histórias como esboço do devir de forças, atua como dispositivo subversivo produzindo diferenciações, redirecionando vetores de forças, produzindo focos de resistência ao provocar uma problematização das condições culturais e políticas engessadas, rígidas e naturalizadas. 


\section{Referências}

ARTIÈRES, Philippe, BERT, Jean-François, POTTE-BONNEVILLE, Mathieu e REVEL, Judith. Apresentação. In: FOUCAULT, Michel. A grande estrangeira: sobre literatura. Trad. Fernando Scheibe. 1 ed. Belo Horizonte: Autentica Editora, 2016. BLANCHOT, Maurice. A literatura e o direito a morte. In: A parte do fogo. Rio de Janeiro: Rocco, 1997.

DELEUZE, Gilles. Pensamento Nômade. In: MARTON, Scarlett (org.). Nietzsche hoje? Colóquio de Cerisy. Trad. Milton Nascimento e Sônia Salzstein Goldberg. São Paulo: Brasiliense, 1985, p. 56-76.

DELEUZE, Gilles. Foucault. São Paulo: Brasiliense, 2005.

FOGEL, Gilvan. O homem doente do homem e a transfiguração da dor: uma leitura de Da visão e do enigma, em Assim falava Zaratustra, de Frederico Nietzsche. Rio de Janeiro: Mauad X, 2010.

FOUCAULT, Michel. Qu'est - ce que les Lumières?. In: Dits Et Écrits, vol. IV. Paris: Gallimard, 1994, 679-688.

FOUCAULT, Michel. Foucault. In: Ditos e Escritos vol.5: ética, sexualidade e política. Trad. Elisa Monteiro, Inês Autram Dourado Barbosa. 2 ed. Rio de Janeiro: Forense Universitária, 2006a, p. 234-239.

FOUGAULT, Michel. A Hermenêutica do Sujeito. $2^{\text {a }}$ ed. São Paulo: Martins Fontes. $2006 \mathrm{~b}$.

FOUCAULT, Michel. El poder psiquiátrico. Trad. Horácio Pons. Buenos Aires: Fondo de Cultura Económica, 2007a.

FOUCAULT, Michel. Vigiar e Punir: Nascimento da Prisão. $34^{a}$ Ed. Tradução de Raquel Ramalhete. Petrópolis: Vozes, 2007.

FOUCAULT, Michel. A arqueologia do saber. Tradução de Luiz Felipe Baeta Neves. $7^{\text {a }}$ edição. Rio de Janeiro: Forense Universitária, 2008.

FOUCAULT, Michel. Distância, aspecto, origem. In: Ditos e Escritos vol. 3: estética: literatura e pintura, música e cinema. $2^{\mathrm{a}}$ ed. Rio de Janeiro: Forense Universitária, 2009 , p. $60-74$.

FOUCAULT, Michel. Conversa com Michel Foucault. In: Ditos e Escritos vol. 6: repensar a política. Rio de Janeiro: Forense Universitária, 2010a, p. 289 - 346.

FOUCAULT, Michel. Os intelectuais e o poder. In: Microfísica do poder. São Paulo: Graal, 2010b, p. 69-78.

FOUCAULT, Michel. O que é a Crítica? [Crítica e Aufklärung]. Tradução, introdução e notas de Fabiano Lemos. 2013.

KLOSSOWSKI, Pierre. Nietzsche y el círculo vicioso. Trad. Roxana Páez. Buenos Aires: Altamira, 1995.

NASSER, Eduardo. Nietzsche e a busca pelo seu leitor ideal. In: Cadernos Nietzsche. São Paulo, v.I n.35, p. 33-56, 2014.

NEHAMAS, Alexander. Nietzsche, la vida como literatura. Tradução: Ramón J. Garcia. Cidade do México: Fondo de Cultura Económica, 2002.

NIETZSCHE, Friedrich. Ecce Homo. Trad. Paulo César de Souza. São Paulo: Companhia das Letras, 1995.

NIETZSCHE, Friedrich. Genealogia da Moral: uma polêmica. Trad. Paulo César de Souza. São Paulo: Companhia das Letras, 1998. 
NIETZSCHE, Friedrich. Humano, demasiado humano: um livro para espíritos livres. Trad. Paulo César de Souza. São Paulo: Companhia das Letras, 2000. Versão on-line disponibilizada e digitalizada por Le Livros.

NIETZSCHE, Friedrich. Além do bem e do mal. Tradução de Paulo César de Souza. São Paulo: Companhia das Letras, 2001a.

NIETZSCHE, Friedrich. A Gaia Ciência. Trad. Paulo César de Souza. São Paulo: Companhia das Letras, 2001b.

NIETZSCHE, Friedrich. Crepúsculo dos ídolos. Trad. Paulo César de Souza. São Paulo: Companhia das Letras, 2006.

NIETZSCHE, Friedrich. Assim falou Zaratustra. Trad. Paulo César de Souza. São Paulo: Companhia das Letras, 2011 a.

NIETZSCHE, Friedrich. Vontade de potência. Trad. Mário Ferreira dos Santos. Petrópolis: Vozes, 2011 b.

SAAR, Martin. Underistandin Genealogy: History, Power, and the Self. In: Journal of the Philosophy of History 2 (2008) 295-314.

Autor(a) para correspondência: Bruno Abilio Galvão,Universidade do Estado do Rio de Janeiro, Rua São Francisco Xavier, 524, sala 9037 - bloco F. Maracanã, 20550-900, Rio de Janeiro - RJ, Brasil. brunoabiliogalvao@hotmail.com 